\title{
Abrindo trilhas e consolidando caminhos: reflexóes sobre minha trajetória profissional
}

\author{
Marisa Cotta Mancini \\ Professora Titular, Departamento de Terapia Ocupacional e Programa de Pós-graduação em Ciências da \\ Reabilitação, Pró-Reitora Adjunta de Pesquisa, Universidade Federal de Minas Gerais - UFMG, \\ Belo Horizonte, MG, Brasil
}

\begin{abstract}
Resumo: O presente Ensaio visa descrever trechos de minha história e minha trajetória profissional, tendo como base o Memorial apresentado para o Concurso para Professora Titular, no Departamento de Terapia Ocupacional da Universidade Federal de Minas Gerais, em 2010. Desde o início de minha formação, o desejo pelos estudos e contribuições na produção de conhecimento sobre reabilitação e desenvolvimento infantil marcaram minha trajetória. A mudança do paradigma de reabilitação mostrou-se fundamental na estruturação de tais pesquisas. Para fundamentação de meu trabalho, a busca por aportes de estudo e pesquisa no exterior, contribuíram para o interesse em buscar instrumentos de avaliação que pudessem informar sobre o desenvolvimento infantil e, desta forma, pautar ações e intervenções, bem como investigação e produção científica. Tal interesse desencadeou um processo de tradução e adaptação de testes funcionais infantis e contribuiu para o desenvolvimento de estudos e linha de pesquisa acerca da funcionalidade de crianças com diferentes condições de saúde e incapacidade. O trabalho interdisciplinar, junto ao binômio ensino-pesquisa, marcou e continua a impactar meus caminhos, sabendo que muito ainda tenho para caminhar e nas trilhas que estão por vir, vou rompendo, inovando e (re) construindo; não tenho vontade de parar.
\end{abstract}

Palavras-chave: Pesquisadores, Terapia Ocupacional, Desenvolvimento Infantil, Reabilitação.

\section{Opening trails and consolidating paths: reflections about my professional trajectory}

\begin{abstract}
The present essay aims to describe passages from my professional history and trajectory, based on the Memorial presented for the full professor application process, at the Department of Occupational Therapy from the Federal University of Minas Gerais, in 2010. Since the beginning of my academic training, the desire to study and contribute with the body of knowledge in rehabilitation and child development marked my trajectory. The change in rehabilitation paradigm played essential role to structuring such research. To help ground my work conceptually, the search for studying and researching abroad contributed to the interest in bringing assessment tools that could inform about child development and, thus, support actions and interventions, as well as scientific investigation and production. Such interest unchained a process of translating and adapting functional tests targeted at children; it contributed to the development of studies and a line of research about functioning of children with different health conditions and disability. The interdisciplinary work, along with the binomial teaching-research, marked and continue to impact my paths, knowing that I still have much further to go and the trails that are there to come, I go breaking away, innovating and (re)constructing; I do not wish to stop.
\end{abstract}

Keywords: Research Personnel, Occupational Therapy, Child Development, Rehabilitation.

Autor para correspondência: Marisa Cotta Mancini, Escola de Educação Física, Fisioterapia e Terapia Ocupacional,

Universidade Federal de Minas Gerais, Av. Presidente Antônio Carlos, 6627, Campus Pampulha, CEP 31270-901,

Belo Horizonte, MG, Brasil, e-mail: mcmancini@ufmg.br

Recebido em 27/2/2012; Aceito em 10/4/2012. 
Tudo o que chega, Chega sempre por alguma razão. Fernando Pessoa

\section{Apresentação}

Dando continuidade à sessão de apresentação da trajetória de pesquisadores terapeutas ocupacionais, inaugurada pelos Cadernos de Terapia Ocupacional da UFSCar, descrevo parte do meu memorial, requisito parcial para o concurso de professor titular, da Universidade Federal de Minas Gerais, em 2009.

No Memorial, descrevi minha história e minha trajetória profissional. Tal história não se resume a uma sucessão de fatos e acontecimentos, mas é contada por minha própria subjetividade, significando o passado, o presente e o futuro, bem como seus ritmos. Hoje, ao contemplar minha própria trajetória profissional, tenho a sensação de realização e o sentimento de estar valendo a pena.

\section{Exórdio: de onde venho}

Minha escolha profissional pela Terapia Ocupacional pautou-se no interesse pessoal em trabalhar com crianças com deficiência e em ajudar as pessoas, desencadeado pelo contato com a irmá de uma de minhas amigas, que tinha síndrome de Down. Além disso, desejava ingressar em um curso que não fosse tradicional, buscando uma profissão diferente das que as pessoas conheciam. Enquanto me empenhava para concluir o científico, me envolvia com procedimentos para realização de intercâmbio nos Estados Unidos e, também, prestei vestibular na Universidade Federal de Minas Gerais (UFMG) para o curso de Terapia Ocupacional. A notícia de minha aprovação foi concomitante à concretização do processo de intercâmbio no exterior e em janeiro de 1982 viajei para a cidade de Hawarden, no estado de Iowa, Estados Unidos. Enquanto isso, providenciei o trancamento da minha matrícula no Departamento de Fisioterapia e Terapia Ocupacional da Escola de Educação Física, da UFMG, para o ano de 1982.

Durante um ano, morei e convivi com quatro famílias americanas, que me ofereceram experiências inesquecíveis. Foi uma experiência muito enriquecedora para mim, pois aos 18 anos de idade tive a oportunidade de viver uma outra cultura, compreender valores que eram diferentes daqueles com os quais eu estava acostumada a conviver, além, é claro, de aprimorar a minha fluência na língua inglesa, que mais tarde abriu muitas outras oportunidades em minha vida.
A experiência vivenciada nesse período serviu para fundamentar a construção de toda uma estrutura de vida, interferindo diretamente nas definiçóes de metas e planos pessoais e profissionais subsequentes. $\mathrm{Da}$ minha herança familiar, importantes valores foram consolidados e direcionaram escolhas posteriores: o incômodo com a suficiência do que se sabe e do que se tem disponível para aprender, a coragem para romper com o status quo estabelecido e buscar o novo; a determinação, dedicação e empenho para inovar, percorrendo caminhos em locais distantes, que para alguns pareciam impossíveis de serem seguidos em toda a sua extensão. Entendi que a liberdade é conquistada diante de possibilidades de escolhas, que têm que ser criadas e pautadas em princípios de ética e respeito humano.

\section{Início do meu caminhar: por onde andei}

Em março de 1983, iniciei o curso de graduação em Terapia Ocupacional na UFMG. Nesse momento, pouco conhecia sobre a Universidade, a estrutura curricular do curso e as possibilidades de atuação do terapeuta ocupacional, mas o meu interesse já havia sido definido pela área de desenvolvimento infantil. Embora eu não conhecesse os procedimentos de avaliação e de intervenção da profissão, e muito menos as diferentes doenças que afetam crianças e podem resultar em deficiências, desejava trabalhar com essa clientela. Tal motivação acompanhou-me por todo o curso de graduação, influenciando minhas escolhas de disciplinas optativas e de estágios curricular e extracurricular, bem como nos cursos de pós-graduação (mestrado e doutorado).

Quando me formei, tinha o desejo de, no futuro, retornar a esta instituiçấo de ensino na qualidade de docente. Eu desejava romper as barreiras do que era conhecido e buscar mais, queria suprir de alguma forma as limitações teóricas e científicas que fizeram parte de minha formação no curso de graduação. Felizmente, esse sentimento de insatisfação e desejo de buscar aprofundamento teórico-prático não era exclusivamente meu. $\mathrm{Na}$ época, eu namorava um estudante do curso de graduaçáo em Fisioterapia da UFMG, Sérgio Teixeira da Fonseca, que acabava de se formar e também não se sentia preparado para o exercício profissional. Fomos orientados a pleitear mestrado no exterior. A princípio, a ideia parecia estimulante, mas, ao mesmo tempo, tínhamos a sensação de que o mestrado, nesse momento, seria um fruto proibido para dois recém-formados, uma vez que nenhum dos nossos professores tinha tal titulação. Se, por um lado, o mestrado no exterior 
parecia algo ousado demais, por outro ficamos extremamente motivados com a possibilidade. Cabe ressaltar que, até 2002, os terapeutas ocupacionais que buscavam seus mestrados o faziam em áreas afins no Brasil ou em Terapia Ocupacional no exterior, visto a inexistência de programas na área no País (DRUMMOND, 1999).

Optamos pela University of Alberta, no Canadá, e, em junho de 1987, recebemos a resposta de aceite; em seguida, da concessão de bolsa para mestrado no exterior, pela CAPES. Sentimentos de felicidade, surpresa e perplexidade se misturavam enquanto me organizava para ir cursar o mestrado em Terapia Ocupacional. Casei-me no dia 16 de agosto e no dia 23 do mesmo mês embarcávamos, Sérgio e eu, para o Canadá. A viagem foi um voo rumo ao desconhecido.

A Faculty of Rehabilitation Medicineda University of Alberta sediava os departamentos de Terapia Ocupacional, Fisioterapia e de Fonoaudiologia e sua estrutura administrativa e acadêmica priorizava o rigor no ensino e na pesquisa.

Minha orientadora, a Professora Dra. Laura Krefting, desenvolvia projetos de reabilitaçáo baseada na comunidade, no Canadá e na Indonésia, com financiamento do governo canadense. Como meu interesse estava definido na área de desenvolvimento infantil, a Dra. Laura Krefting apresentou-me para a Dra. Martha Piper, professora do curso de Fisioterapia, que na época era a diretora da Faculty of Rehabilitation Medicine, e passou a ser minha coorientadora.

Defini meu projeto de dissertação (MANCINI, 1989) na linha de pesquisa da Dra. Martha Piper e tive como colega mais próxima uma fisioterapeuta da cidade de Edmonton, chamada Johanna Darrah. A Dra. Martha Piper era uma pesquisadora renomada por seus projetos e publicaçóes sobre o impacto do nascimento pré-termo no desenvolvimento infantil, possuindo verbas de diferentes agências de fomento. A proximidade com a equipe da Dra. Martha Piper ensinou-me que a comunicação dos resultados de projetos de pesquisa, por meio de publicaçóes em revistas científicas, era uma parte fundamental do processo de investigação científica. Ao final do meu mestrado, a Dra. Martha Piper havia acabado de receber vultoso financiamento para o desenvolvimento de um novo teste para avaliar o desenvolvimento infantil. Mais tarde, esse projeto consistiria no doutorado de Johanna Darrah e culminaria na publicação do Aberta Infant Motor Scales (AIMS) (PIPER; DARRAH, 1994), um teste do desenvolvimento motor infantil bastante conhecido e utilizado mundialmente na clínica e na pesquisa.

O mestrado em Terapia Ocupacional na Faculty of Rehabilitation Medicine, da University of Alberta, contribuiu sobremaneira para a consolidação de minha formação profissional, principalmente no que tange à fundamentação teórica. Serviu também para introduzir-me no processo de investigação científica, a partir dos cursos de Metodologia e de Estatística e da minha participação em um grupo de pesquisa considerado de referência na área de desenvolvimento infantil.

Enquanto finalizávamos nossos respectivos projetos de pesquisa, Sérgio e eu tomamos conhecimento da abertura de vagas para docente no Departamento de Fisioterapia e Terapia Ocupacional, da Escola de Educação Física da UFMG (uma vaga na área de deficiência mental) e de Fisioterapia (uma vaga). Era a oportunidade que sonhávamos; antes de termos finalizado nossos mestrados, fomos ao Brasil prestar concurso. Infelizmente, não fomos aprovados e logo retornamos ao Canadá para concluir nossos cursos.

Em outubro de 1989, após concluir nossos mestrados, retornamos definitivamente para o Brasil. Novas vagas foram abertas para os cursos de Terapia Ocupacional e de Fisioterapia na Universidade Federal de Minas Gerais. Inscrevemo-nos e nos preparamos para prestar concurso público, desta vez com nossos respectivos títulos de mestrado. O resultado foi gratificante e em fevereiro de 1990 eu assumia o cargo de Professora-Assistente do Departamento de Terapia Ocupacional, em regime de 40 horas DE, na Escola de Educação Física da UFMG. Começava naquele momento uma nova fase da minha vida profissional.

\section{Um novo caminho: definindo trilhas}

Iniciei minhas atividades docentes como supervisora de estágio curricular dos alunos do último ano do curso de graduação em Terapia Ocupacional. Começava ali o meu primeiro desafio da carreira docente: contribuir na fundamentação teórica e na sistematização da prática dos alunos do curso de graduação em Terapia Ocupacional. Engajada nesse compromisso, e com a concordância dos alunos, começamos a estruturar a prática clínica com base no Modelo da Ocupação Humana (KIELHOFNER, 1985). Em recompensa a meu empenho, fui presenteada com uma homenagem especial na formatura da minha primeira turma de alunos. Essa missão que defini para minha carreira 
acadêmica foi, posteriormente, evidenciada na busca de aprimoramento dos processos de avaliação e de intervenção em Terapia Ocupacional.

Com o afastamento de uma colega docente do curso para programa de doutorado no exterior (professora Lívia de Castro Magalhães), em agosto de 1991, entrei para o projeto de extensão e pesquisa "Avaliaçáo e acompanhamento do bebê de alto-risco no primeiro ano de vida" (ACRIAR) ocorrido no Complexo Hospital das Clínicas da UFMG. Esse era um projeto interdepartamental que contava com a participação de professores dos departamentos de Fisioterapia, Terapia Ocupacional, Pediatria, Neurologia e Psiquiatria. Tinha como objetivo avaliar e documentar o processo de desenvolvimento de crianças de risco nascidas na maternidade do Hospital das Clínicas da UFMG, orientar os pais em relação ao desenvolvimento de seu filho, além de disponibilizar orientaçóes para estimulação e manuseio adequados das crianças na rotina diária. A adesão a esse projeto viabilizou o início de minhas atividades de pesquisa na carreira docente. A partir do conhecimento teórico e metodológico adquirido especificamente nessa área (desenvolvimento de bebês pré-termo) durante o meu programa de mestrado, inseri-me com o intuito de dar continuidade à prestação de serviço, mas também com o forte desejo de desenvolver pesquisa (que, na ocasiáo, ainda era incipiente nesse projeto) e produção científica. Em 1992, foi publicado o primeiro artigo científico da minha carreira acadêmica, sendo também a primeira publicação com resultados provenientes desse projeto (MANCINI et al., 1992). Eu me sentia fascinada pela pesquisa e a produçáo científica na área de desenvolvimento infantil. A cada estudo concluído, surgiam novas perguntas e esse processo resultou em aprofundamento dos temas investigados e dos métodos científicos utilizados.

Esse período inicial de minha carreira docente pode ser definido como fase de assimilaçáo ou de exploração ${ }^{1}$, na qual os conhecimentos adquiridos no mestrado foram utilizados e aplicados no ensino e na pesquisa. A investigação científica mantinha meu interesse e motivação, apesar de ainda ser uma iniciante. Entretanto, começava a sentir a necessidade de aprofundar meus conhecimentos, principalmente em Metodologia e Estatística, de forma a me instrumentalizar melhor para continuar desenvolvendo pesquisas na área de desenvolvimento infantil. Tinha interesse também em ampliar os projetos para temas a serem investigados em diferentes grupos clínicos (crianças com diferentes condiçốes de saúde) e, para tanto, precisava enriquecer meus conhecimentos acerca do processo de incapacidade. Daí surgiu o interesse por pleitear o doutorado no exterior.

Procurava adquirir mais conhecimentos sobre métodos e técnicas para o desenvolvimento de pesquisa, no intuito de possibilitar sofisticação teórica e metodológica das investigaçóes científicas na área de desenvolvimento infantil. Juntamente com o Sérgio, comecei novamente a maratona de pedido de liberação. Conseguimos a liberação institucional, fomos aceitos pela Boston University, com a concessão de bolsa pelo $\mathrm{CNPq}$, e partimos para os Estados Unidos em agosto de 1993, na companhia de nossa filha Daniela, nascida em 1991. A escolha pela Boston Universityfoi subsidiada pela qualidade da estrutura curricular e do corpo docente e pelo fato de possuir programas de doutorado em Terapia Ocupacional e em Fisioterapia em nossas respectivas áreas de interesse.

O programa de doutorado em Terapia Ocupacional era localizado no Sargent College of Health \& Rehabilitation Sciences, juntamente com programas em Fisioterapia, Fonoaudiologia, Treinamento Atlético, Aconselhamento em Reabilitação, Nutrição e outros. Naquela época, o corpo docente desse programa incluía nomes bastante conhecidos na área da Terapia Ocupacional, como Catherine Trombly, Anne Henderson, Sharon Cermak, e também professores recém-contratados com sólida formação teórica e metodológica, como Wendy Coster e Linda-Tickle Degnen, que haviam concluído o doutorado na Harvard University.

Minha orientadora, Dra. Wendy Coster, teve sua formaçáo na Psicologia do Desenvolvimento e havia acabado de desenvolver e publicar um teste para avaliaçáo funcional infantil, chamado Pediatric Evaluation of Disability Inventory (PEDI) (HALEY et al., 1992).

Durante o primeiro ano no programa de doutorado, os estudantes deveriam desenvolver um projeto sugerido pelo orientador. No meu caso, foi-me sugerida a análise de alguns dados já coletados com o PEDI em crianças com paralisia cerebral. Naquele momento, além de aprofundar em teorias conhecidas, tive a oportunidade de ampliar meus conhecimentos aprendendo novas propostas teóricas como a "Abordagem Ecológica", de James Gibson (GIBSON, 1986), a "Abordagem dos Sistemas Dinâmicos" (KELSO, 1995) e a "Abordagem Sociocultural", de Barbra Rogoff (ROGOFF, 1990).

No interior de um projeto maior, aliado ao meu grande interesse pela Estatística, decidimos que o meu projeto de doutorado (MANCINI, 1997) 
envolveria o uso de um novo modelo de análise estatística, denominado Classification and Regression Trees (CART) ou Recursive Partitioning, que estava começando a ser utilizado em pesquisas na área da saúde. O Professor Ralph D’Agostino era um dos poucos pesquisadores que tinham familiaridade com esse tipo de modelo preditivo.

A Dra. Wendy Coster é uma pesquisadora à frente de seu tempo, não só para a Terapia Ocupacional, mas também considerando as áreas da saúde e reabilitação. Muitos de seus projetos de pesquisa centravam-se em conceitos que só alguns anos mais tarde seriam amplamente discutidos na literatura. Por exemplo, ela é autora do teste funcional (Pediatric Evaluation of Disability Inventory - PEDI), que utiliza terminologia voltada para a lógica da funcionalidade, em uma época (1992) na qual o modelo mundialmente vigente destacava somente a visão restrita da incapacidade (WORLD..., 1980). Só muitos anos mais tarde (2001) a Organização Mundial de Saúde publicaria o modelo de funcionalidade (WORLD..., 2001). O meu projeto de doutorado foi outro exemplo desse pioneirismo e, como resultado, conseguimos publicá-lo em uma das melhores revistas científicas da área de reabilitação na época (MANCINI et al., 2000).

Em setembro de 1997, após concluirmos nossos doutorados, retornamos ao Brasil e reassumi meus encargos junto ao Departamento de Fisioterapia e Terapia Ocupacional da Escola de Educação Física, UFMG. Nesse momento, tive a sensação de que havia conseguido o aprofundamento teórico e metodológico almejado.

\section{Meu caminhar: consolidando trilhas}

Desde meu retorno à UFMG após o doutorado, o percurso acadêmico desenvolveu-se simultaneamente em trilhas distintas, as quais ilustram o impacto da minha formação no exterior em diferentes atividades realizadas.

\subsection{Trilha 1: exercendo a interdisciplinaridade nas parcerias}

Durante todo o meu percurso, nunca caminhei sozinha. Nesse processo, estabeleci muitas parcerias que contribuíram sobremaneira para o meu desenvolvimento como docente e pesquisadora. Tais parcerias foram efetivadas não só com colegas do curso de Terapia Ocupacional, mas também com muitos outros profissionais e docentes da Fisioterapia, Educação Física, Medicina (Pediatria e Neurologia), entre outras áreas. A interdisciplinaridade tem permeado todas as minhas atividades de ensino, pesquisa e extensão e está presente nas demais trilhas que descrevo a seguir. Em parceria, sempre lutei por uma causa que fosse maior do que eu e que pudesse contribuir positivamente para um grupo.

\subsection{Trilha 2: novas propostas para o ensino}

Ao retomar minhas atividades acadêmicas no segundo semestre de 1997, comecei implementando um novo formato para as disciplinas e projetos que já lecionava ou desenvolvia e, posteriormente, fui envolvendo-me em novas atividades.

Em relação ao estágio curricular de alunos do nono período do curso de graduação em Terapia Ocupacional, em parceria com a colega Professora Zélia Araújo Cotta Coelho, modificamos a estrutura dessa disciplina, com base nas recentes propostas da Federação Mundial de Terapeutas Ocupacionais (WFOT) para a formação e a prática profissional. Começamos a utilizar testes funcionais para avaliar crianças com distúrbios neuromotores, incluindo o Pediatric Evaluation of Disability Inventory (PEDI) e o teste Alberta Infant Motor Scales (AIMS). Como todos esses testes disponibilizam escores quantitativos, eles foram utilizados para mapear, graficamente, o perfil de evolução de cada criança. A análise gráfica do perfil evolutivo individualizado permite a visualização do ritmo e do padrão de mudanças observados na criança ao longo de seu processo de intervenção no setor de Terapia Ocupacional. A partir dessa análise, é possível discutir os possíveis efeitos da intervenção em cada caso. E para os que têm estabilizaçáo no quadro de funcionalidade, é feita criteriosa reflexão sobre a adequação e pertinência das estratégias terapêuticas empregadas.

Um outro instrumento de avaliação adotado foi o Canadian Occupational Performance Measure (COPM), no qual, por meio de entrevista estruturada, as mães de crianças com deficiência informam sobre as limitaçóes funcionais vivenciadas pela criança nas áreas de autocuidado, lazer e trabalho (escola) e avaliam o desempenho da criança bem como a própria satisfação em relação ao desempenho funcional da criança. A informação disponibilizada pelo COPM é utilizada para definir e priorizar objetivos terapêuticos relevantes para o cliente.

Essas e outras propostas ilustram meu empenho em despertar no estudante e no profissional o espírito crítico para com a prática, reavaliando suas condutas terapêuticas e buscando implementar um 
raciocínio clínico (MANCINI; COELHO, 2008) cada vez mais elaborado.

Uma outra contribuição que venho prestando ao ensino refere-se ao conteúdo de Metodologia da Investigação Científica. Assumi, em 1999, juntamente com as Professoras Raquel Rodrigues Britto e Rosana Ferreira Sampaio, do curso de Fisioterapia, a tarefa de estruturar e ministrar essa disciplina para os estudantes da graduação. Posteriormente, o conteúdo também foi colocado sob minha responsabilidade e da Professora Rosana Ferreira Sampaio nos programas de Especialização em Fisioterapia, Especialização em Terapia Ocupacional e Pós-Graduação em Ciências da Reabilitaçáo (cursos de mestrado e de doutorado).

Ainda no que tange ao ensino, participei da Comissão de Elaboraçáo da Nova Proposta Curricular do curso de Graduação em Terapia Ocupacional. O novo currículo do curso de Graduação em Terapia Ocupacional traz uma proposta pioneira e inovadora, consistente com as recentes recomendaçóes da Organização Mundial de Terapeutas Ocupacionais (WFOT), com as tendências teóricas atuais e incorporando diferentes metodologias de ensino, incluindo as ativas.

Vale destacar outra experiência internacional que teve contribuição importante em minha formação, no investimento em prática baseada em evidências na graduação e na pós-graduação. Em fevereiro de 2004, recebi carta-convite da Fundação Americana de Terapia Ocupacional (AOTF) e da Associação Americana de Terapia Ocupacional (AOTA) para participar, como representante da América do Sul, da Conferência Internacional sobre Prática Baseada em Evidências na Terapia Ocupacional, que aconteceria em um subúrbio americano próximo da cidade de Washington, D.C. Esse evento reuniu representantes de diversas partes do mundo, incluindo grandes lideranças da Terapia Ocupacional, para unirem-se na força-tarefa de estruturar e difundir mundialmente a prática baseada em evidências em Terapia Ocupacional como estratégia de ensino e eixo fundamental da prática clínica.

\subsection{Trilha 3: estruturando laboratórios e programas acadêmicos}

Em 1998 participei da comissão que elaborou o "Projeto de estruturação e montagem dos laboratórios de pesquisa para os departamentos de Fisioterapia e de Terapia Ocupacional", que aconteceu juntamente com o "Projeto de expansão do espaço físico", ampliando as suas dependências. Esse projeto foi contemplado no Fundo FUNDEP/1998-1999 da UFMG.
Com a experiência de pós-graduação no exterior, planejei, juntamente com a Professora Lívia de Castro Magalhães, uma estrutura de laboratórios para pesquisas em desenvolvimento infantil semelhante à existente na Boston University, com duas salas para atividades com as crianças e uma sala intermediária de observação. Essa estrutura foi inspirada na Câmara de Gesell, elaborada para observaçáo do comportamento de crianças em diferentes situaçóes. Uma das salas foi montada com equipamentos suspensos para utilização em intervençôes da Terapia de Integração Sensorial e a outra para atividades escolares.

Uma vez montada a estrutura inicial de laboratórios para pesquisa, era importante envidar esforços no desenvolvimento de um programa de pós-graduação stricto senso.

Precisávamos, como grupo, ousar e criar condições para avançarmos com os projetos de pesquisa. Deu-se início, então, ao processo de discussão de uma proposta para participação dos docentes em programa de pós-graduação stricto senso. Em reunióes, ficou decidido que os departamentos envolvidos iriam trabalhar para incluir os docentes de Fisioterapia e de Terapia Ocupacional em uma nova área de concentraçáo no Programa de Mestrado em Educação Física. Entretanto, por recomendação do representante da área na CAPES, a criação de uma outra área de concentraçáo foi descartada e os departamentos de Fisioterapia e de Terapia Ocupacional foram estimulados a elaborar um projeto próprio de pós-graduaçáo stricto senso. Naquela época, o reduzido número de docentes com titulação de doutorado no Departamento de Terapia Ocupacional ( $\mathrm{n}=2)$ associado ao interesse comum pelos modelos de funcionalidade e incapacidade humana resultou em uma proposta de parceria dos departamentos de Fisioterapia e de Terapia Ocupacional no desenvolvimento do Programa de Pós-Graduação em Ciências da Reabilitação. Durante a elaboração da proposta, fui, juntamente com outros docentes, responsável pela definição das bases epistemológicas do Programa.

Na redaçáo do projeto, a Professora Rosana Ferreira Sampaio e eu sugerimos a utilização do modelo da Organização Mundial de Saúde (OMS) vigente na época (WORLD..., 1980) como estrutura conceitual para fundamentar o currículo, bem como a área de concentração (desempenho funcional humano) e respectivas linhas de pesquisa do programa de pós-graduação em Ciências da Reabilitação.

No ano 2000, o projeto para implantaçáo do Curso de Mestrado em Ciências da Reabilitaçáo foi enviado pela Escola de Educação Física para 
a Reitoria e, no final de 2001, foi aprovado pela CAPES com nota 4.

Para a Terapia Ocupacional, tratava-se de um projeto pioneiro, uma vez que náo havia programa de pós-graduação stricto senso no País. Para a Fisioterapia, este era o segundo programa stricto senso no Brasil, tendo sido precedido pelo de pós-graduaçáo em Fisioterapia da Universidade Federal de São Carlos.

Com o resultado da avaliaçáo trienal da CAPES (triênio 2001-2003), tendo o programa de Mestrado em Ciências da Reabilitação recebido nota 5, iniciamos discussão sobre ampliação do programa para incluir curso de doutorado. Mais uma vez, a Professora Rosana Sampaio e eu redigimos a parte inicial do projeto, fundamentando a estrutura do programa e do novo curso de doutorado no modelo da Classificação Internacional de Funcionalidade Incapacidade e Saúde (CIF) (WORLD..., 2001). Em agosto de 2006, ingressavam no programa os primeiros alunos do curso de doutorado.

As experiências adquiridas na comissão de avaliação trienal da CAPES e como Professora Orientadora no programa de pós-graduaçáo em Ciências da Reabilitação contribuíram para o convite feito por colegas do Departamento de Terapia Ocupacional da Universidade Federal de São Carlos para compor a proposta de novo curso de mestrado em Terapia Ocupacional na qualidade de Professora Colaboradora, a qual foi, em novembro de 2009, aprovada e consistiu no primeiro curso de mestrado em Terapia Ocupacional no País.

\subsection{Trilha 4: Sinergismo pesquisa-extensão}

Após meu doutorado, retornei ao projeto "Avaliação e acompanhamento da criança de risco" (ACRIAR). Nesse momento, o interesse pela prestação de serviços a partir da avaliação de crianças e orientação de pais era novamente compartilhado pela motivação com a investigação e a produção científica. $\mathrm{O}$ aprofundamento teórico obtido no doutorado subsidiou a formulação de muitas perguntas e consequente desenvolvimento de projetos de pesquisa na área de desenvolvimento infantil, em parceria com colegas que trabalhavam no ACRIAR e consequentes publicações.

Com isso, tornei-me pesquisadora do grupo de pesquisa credenciado no CNPq, intitulado Avaliação do Desenvolvimento e Desempenho Infantil. Durante os seis anos em que participei do projeto ACRIAR, aprendi muito, principalmente, que o impacto do nascimento pré-termo deve ser entendido além dos desfechos do desenvolvimento da criança. A interrupção do período de gestação e o consequente nascimento de um bebê pré-termo em uma família, que geralmente é acompanhado de vulnerabilidade clínica da criança nos períodos peri e pós-natal, levam à ressignificação do papel materno, criando uma rede de relaçóes familiares que influencia diretamente a criança e seu processo de desenvolvimento. Esta problemática não deve ser caracterizada exclusivamente como biológica nem ambiental, mas sim como um fenômeno biopsicossociocultural.

Mais tarde, com a eminência do início do programa de pós-graduação em Ciências da Reabilitação em 2002, desliguei-me do projeto ACRIAR, por sentir necessidade de desenvolver uma estrutura própria de pesquisa, orientando alunos em projetos de mestrado e, mais tarde, de doutorado.

\subsection{Trilha 5: Ultrapassando os muros da UFMG - alcançando serviços de reabilitação}

A partir do projeto de tradução e adaptação cultural do teste PEDI, fui solicitada a informar e formar profissionais de diferentes centros de reabilitação sobre esse novo teste funcional. Essa tarefa tem sido solicitada até a presente data.

O treinamento dos profissionais em instituições possibilitou que esses serviços de reabilitação começassem a fazer uso sistematizado de instrumentação funcional para documentar os desfechos das diferentes intervençóes profissionais realizadas em suas respectivas instituiçôes.

Mais recentemente, tenho visitado dois núcleos de reabilitação infantil da regiấo Nordeste que prestam atendimento a crianças com deficiência, principalmente com diagnóstico de paralisia cerebral. O objetivo dessas visitas está centrado na formação dos profissionais e na orientação da equipe para a implementação de um modelo de prática sistematizada, com foco na funcionalidade.

A interface e parceria com serviços de reabilitação infantil têm se constituído em uma forma de legitimar o conhecimento produzido na academia, tornando-o acessível aos serviços e aos profissionais que trabalham com crianças com deficiência. 


\subsection{Trilha 6: Trilhando a administração}

No período compreendido entre maio de 2000 e maio de 2002, assumi a subchefia do Departamento de Terapia Ocupacional, juntamente com a Professora Marcella Guimarães Assis Tirado, como chefe.

As metas definidas para essa gestão incluíram criar curso de pós-graduação stricto senso (nível mestrado), dar continuidade ao processo de qualificação docente, modificar os critérios para capacitação e, ainda, reformar e ampliar a estrutura física do Departamento de Terapia Ocupacional com a construção de laboratórios para ensino e pesquisa, bem como reforma da estrutura física do setor de Terapia Ocupacional no Complexo Hospital das Clínicas (Ambulatório Bias Fortes). Todas essas metas foram atingidas durante o período.

Fui representante titular no Colegiado de Graduação em Terapia Ocupacional e na Câmara do Departamento de Fisioterapia e Terapia Ocupacional. Desde a separação dos departamentos de Fisioterapia e Terapia Ocupacional, tenho sido sistematicamente representante titular na Câmara do Departamento de Terapia Ocupacional, devido ao reduzido número de professores das categorias de adjunto e, mais recentemente, associado.

A representação da linha de Avaliação do Desenvolvimento e Desempenho Infantil junto ao Colegiado de Pós-Graduação em Ciências da Reabilitação tem sido mantida por mim, pela Professora Lívia Magalhães e, mais recentemente, pela Professora Elyonara Mello de Figueiredo, estabelecendo-se um revezamento entre nós, a cada dois anos, nas funçôes de membro titular e suplente.

\subsection{Trilha 7: Transpondo limites - representações externas}

Essa trilha está sendo percorrida de várias formas, tendo diferentes eventos possibilitado a efetivação em representaçóes de órgãos e instituiçóes externos à UFMG.

Minha participação na Conferência Internacional sobre Prática Baseada em Evidências na Terapia Ocupacional, em junho de 2004, nos Estados Unidos, resultou na indicação de meu nome para compor um grupo especial (International Advisory Group), vinculado à Federação Mundial de Terapeutas Ocupacionais (WFOT-EBP group). Esse grupo tem como objetivos aconselhar e auxiliar a WFOT sobre temas relacionados à prática baseada em evidências (BENNETT et al., 2006). Os trabalhos desenvolvidos nesse grupo com terapeutas ocupacionais da Inglaterra e da Austrália têm sido enriquecedores, participando, por exemplo, do processo de elaboraçáo de documento que define parâmetros de competência sobre prática baseada em evidências, para a WFOT.

Com o início da Pós-Graduação em Ciências da Reabilitação (2002), a Terapia Ocupacional começou a fazer parte de um programa stricto senso no País e inaugurou sua presença efetiva na conhecida Área 21 da CAPES. Naquela época, os programas de pós-graduação em Educação Física, Fonoaudiologia, Fisioterapia e Terapia Ocupacional estavam se mobilizando para compor um fórum de pós-graduação das áreas, que seria organizado por um comitê gestor com representantes das quatro áreas, cuja função seria discutir as especificidades destas frente às demandas crescentes definidas pela CAPES.

Em um dos encontros desse fórum, meu nome foi indicado e fui eleita representante da Terapia Ocupacional junto ao Comitê Gestor do Fórum. Minhas participaçóes nas reunióes permitiram que eu me inteirasse dos diferentes temas e problemas dos programas de pós-graduaçáo, bem como que eu participasse da discussão sobre a definiçáo dos critérios para avaliaçáo dos programas stricto senso. Em agosto de 2007, fui indicada para participar da Avaliação Trienal (triênio 2004-2006) dos Programas de Pós-Graduação em Educação Física, Fonoaudiologia, Fisioterapia e Terapia Ocupacional da CAPES, como representante da Terapia Ocupacional. Foi a primeira vez que a Terapia Ocupacional participou com um representante na comissão de Avaliação Trienal da CAPES.

Em junho de 2007, fui eleita representante suplente da área de Fisioterapia/Terapia Ocupacional junto ao $\mathrm{CNPq}$, em votaçáo realizada pelos pesquisadores nível 1. Em parceria com a Professora Helenice Jane Cote Gil Coury, que era a representante titular, nosso mandato finalizado em 2010, pautou-se na divulgação e cumprimento dos critérios publicados no site do CNPq para avaliação das diferentes solicitaçóes de fomento e de bolsas. Além disso, buscamos junto às instâncias superiores do CNPq mais reconhecimento e atenção às crescentes demandas da área.

Tenho contribuído com alguns periódicos da área e, em especial, com a Revista Brasileira de Fisioterapia (RBF), desde 2004. Nessa época, fui indicada para atuar como membro do corpo Editorial e, em abril de 2009, como membro do corpo de editores da área de Fisioterapia nas Condições Neurológicas (Neuropediatria), bem como análise de artigos de revisão sistemática e metanálise. Em 2009, meu nome foi indicado e aprovado para atuar como editora da RBF. Mais recentemente, fui convidada pelo Editor 
Chefe da revista Occupational Therapy International (Dr. Franklin Stein) para compor o grupo de Editores Associados deste periódico internacional, no período de 2011 a 2016. A consolidação de periódicos é fundamental para a produção de conhecimento dos pesquisadores e dos programas de pós-graduação da área, constituindo, assim, uma importante missão, a qual abraço com muito empenho.

\subsection{Trilha 8: Mais um passo à frente}

Com a elaboração da proposta para o Curso de Doutorado em Ciências da Reabilitação, em 2004, começava a sentir novamente inquietação e vontade de buscar aprofundamento teórico. Esse seria um bom momento para planejar um pós-doutorado no exterior.

Em setembro de 2004, fui membro da comissão organizadora do II Congresso Brasileiro de Comportamento Motor, juntamente com os Professores Sérgio Fonseca (Fisioterapia), Rodolfo Benda e Herbert Ugrinowitsch (Educação Física), que aconteceu na Universidade Federal de Minas Gerais. Fiquei particularmente impressionada com as apresentaçóes do Dr. Michael Turvey e da Dra. Claudia Carello sobre formulaçóes teóricas e investigaçóes científicas centradas na abordagem ecológica. O contato com ambos acenou com a possibilidade de um pós-doutorado na University of Connecticut. Os Professores Michael Turvey e Claudia Carello são diretores do Center for the Ecological Studies on Perception and Action (CESPA), que está vinculado ao Departamento de Psicologia Experimental da University of Connecticut. Trata-se de um centro de excelência reconhecido pelos avanços teóricos, metodológicos e científicos fundamentados nas Abordagens Ecológicas à Percepção-Ação (criada por James Gibson) e Sistemas Dinâmicos. O encontro com Michael e Claudia no Congresso de Comportamento Motor em Belo Horizonte despertou, em ambas as partes, interesse por parcerias. Por um lado, os professores do CESPA procuravam pesquisadores da área da reabilitaçáo, com ênfase nas abordagens teóricas utilizadas e que pudessem fortalecer seus projetos; por outro lado, buscávamos um local com garantida solidez teórica para nosso programa de pós-doutorado.

Em agosto de 2005, embarcávamos para o pós-doutorado nos Estados Unidos com financiamento da CAPES, na companhia de nossas duas filhas, Daniela e Juliana, esta última nascida em 18 de agosto de 1998.

O período passado no CESPA foi permeado de experiências extremamente ricas. Durante o ano em que lá permaneci, tive a honra de conhecer, conversar e fazer contato com expoentes nomes da área de comportamento motor, tais como Scott Kelso, John Scholz, Peter Kugler, Jill Withall, Antony Chemero, Elliot Saltzman, Kenneth Holt, entre outros. Mais uma vez tive a oportunidade de aproximar-me de notáveis referências citadas em minhas pesquisas.

Em agosto de 2006, retornamos ao Brasil e reassumi minhas atividades no Departamento de Terapia Ocupacional e no Programa de Pós-Graduação em Ciências da Reabilitação. O ano que passei no CESPA consolidou algumas tendências e interesses teóricos. $\mathrm{O}$ aprofundamento na Abordagem Ecológica de James Gibson representou um avanço pessoal, com subsequentes contribuiçôes tanto para o programa de Pós-Graduação em Ciências da Reabilitação quanto para a Terapia Ocupacional. As ideias originadas a partir desse período em pós-doutorado no exterior estáo sendo aplicadas em diferentes atividades de pesquisa e de orientação no Departamento de Terapia Ocupacional e nos programas de pós-graduação (lato e stricto senso).

\subsection{Trilha 9: Avançando com a investigação e a produção científica}

Ao final do doutorado, trabalhei na tradução para o português e subsequente utilização da versão traduzida do teste PEDI em minhas pesquisas. Com a autorização e interesse manifestado pelos professores da Boston University em acompanhar e colaborar com os trabalhos de tradução, iniciei o projeto intitulado "Adequação de teste funcional para avaliação do desenvolvimento infantil". Esse projeto consistiu na tradução do formulário de escore do teste PEDI para o português, conforme procedimentos metodológicos descritos na literatura, e consequente utilização da versão traduzida para testar a adequação do conteúdo do teste na avaliaçáo de crianças brasileiras.

A comparaçáo do desempenho de crianças brasileiras com desenvolvimento normal com o desempenho de crianças norte-americanas da amostra normativa do teste PEDI revelou diferenças significativas, sugerindo que as normas norte-americanas poderiam não ser adequadas para servirem de referência no Brasil. Além disso, um conteúdo específico da versão norte-americana do teste PEDI revelou-se inapropriado para avaliação funcional da criança brasileira, sendo então necessária a adequação do conteúdo e dos dados normativos do teste PEDI para que ele pudesse ser utilizado no Brasil. 
A necessidade de ampla divulgaçáo do material traduzido e adaptado às especificidades da cultura brasileira (incluindo manual e formulários de escore) resultou, em 2005, no lançamento oficial da versão brasileira traduzida e adaptada do material do teste PEDI (manual e formulários de escore), possibilitando o acesso de profissionais e estudantes ao instrumento (MANCINI, 2005). Esse material tem sido utilizado na atuação clínica (documentação de desfechos funcionais) e em pesquisas desenvolvidas em diferentes áreas, incluindo terapia ocupacional, fisioterapia, fonoaudiologia, medicina (pediatria, neurologia e ortopedia infantil), psicologia, educação física, entre outras.

As pesquisas de que participei e projetos que venho desenvolvendo foram historicamente marcados por duas fases complementares, com enfoques específicos de investigação. A primeira fase compreendeu o período iniciado com a finalizaçáo do programa de mestrado no exterior e início da carreira docente até o retorno ao Brasil, após programa de doutorado no exterior; a segunda fase teve início mais recente, próximo do período de saída para o pós-doutorado no exterior, e permanece até o presente momento.

As perguntas que fundamentaram a primeira fase do meu processo de investigaçáo científica foram elaboradas a partir dos modelos propostos pela Organização Mundial de Saúde (ICIDH, CIF), respeitando o enfoque na funcionalidade. Os temas dos projetos desenvolvidos estavam voltados para a investigação e caracterização das consequências funcionais de diferentes condiçôes de saúde em crianças, bem como para a identificação das variáveis que interferem na relação entre condição de saúde e funcionalidade.

Dessa forma, foram desenvolvidos estudos sobre paralisia cerebral e funcionalidade, asma infantil e funcionalidade, nascimento pré-termo e funcionalidade e síndrome de Down e funcionalidade, entre outras condiçôes de saúde. Essa mesma temática (i.e., relaçáo entre condição de saúde e funcionalidade) foi também analisada na área de saúde do trabalhador, em parceria com a Professora Rosana Ferreira Sampaio.

Em síntese, os estudos desenvolvidos na primeira fase revelaram que diferentes condiçóes de saúde (i.e., paralisia cerebral, asma, prematuridade, síndrome de Down, lesão de mão, entre outras) resultam em manifestaçôes funcionais diferenciadas e também que uma única condição de saúde apresenta manifestações funcionais distintas em diferentes indivíduos. Além disso, a relação entre condição de saúde e funcionalidade constitui um fenômeno náo linear e multidimensional, sendo importante considerar as particularidades da condição (i.e., gravidade do comprometimento, característica aguda ou controlada da condiçáo) e os fatores do contexto, que podem ser moderadores e/ou mediadores dessa relação. Tais resultados confirmam a manifestação individualizada e a natureza complexa dos processos de funcionalidade e incapacidade humana.

A partir da constatação de que crianças (e adultos) com deficiência são funcionalmente diferentes entre si e também diferentes de crianças (e adultos) normais, o meu interesse começou a voltar-se para o entendimento e aprofundamento sobre o que permeia e causa essas diferenças. Deu-se início, então, ao processo que caracterizou uma mudança de fase nas minhas investigações científicas. Na segunda fase, o meu interesse está direcionado para a compreensão dos seguintes fenômenos: mecanismos que explicam as diferenças funcionais, mudanças no processo de desenvolvimento em crianças normais e em crianças com deficiência e mudanças consequentes de intervençôes terapêuticas utilizadas em reabilitação.

Os estudos desenvolvidos (e em desenvolvimento) na segunda fase do meu processo de investigação científica têm mantido o enfoque na funcionalidade, entretanto, devido à natureza deles (i.e., compreensão dos mecanismos que explicam funcionalidade e variáveis moderadoras/mediadoras de mudanças funcionais), parcerias feitas em projetos desenvolvidos por outros colegas permitiram minha experiência e familiarização com novos métodos de investigação e de análise de dados (i.e., metodologia qualitativa) e com procedimentos para investigação de variáveis específicas (i.e., mecanismos neuromusculares).

O termo função refere-se à interação resultante da troca de energia e de informaçáo entre partes do organismo e entre o indivíduo e seu ambiente (TESIO, 2007). Considerando tal definição, os projetos desenvolvidos nessa segunda fase analisaram as características neuromusculares relacionadas à função manual de crianças com paralisia cerebral, bem como as mudanças nos mecanismos neuromusculares consequentes ao processo de aquisição da marcha em crianças normais e em crianças com síndrome de Down.

Outros projetos estão voltados para a avaliação dos efeitos de intervençôes utilizadas em reabilitação na promoção da funcionalidade em crianças com deficiência.

Mais recentemente, com o retorno ao Brasil, do pós-doutorado CESPA, tenho utilizado a Abordagem Ecológica como referencial teórico (FONSECA et al., 2007) em estudos sobre o 
desenvolvimento das habilidades hápticas em crianças normais e crianças com deficiência.

\section{Marcas que deixei no meu caminhar: uma síntese}

Refletindo sobre meu percurso, identifico duas importantes contribuiçóes para a Terapia Ocupacional e para o campo da reabilitaçáo: a) implementaçáo de um enfoque de atuaçáo centrado no entendimento do processo de funcionalidade; b) pós-graduação, pesquisa e produçáo de conhecimento, em especial na área de desenvolvimento infantil.

\subsection{Implementação do foco na funcionalidade}

Após período de doutoramento no exterior, passei a entender os processos ligados à reabilitaçáo numa perspectiva de funcionalidade, ou seja, priorizando o potencial do indivíduo sendo influenciado diretamente pelas características do contexto. A mudança do modelo inicial (WORLD..., 1980) para o atual (WORLD..., 2001) exige ruptura de conhecimentos previamente estabelecidos, bem como uma nova forma de pensar e de conduzir o raciocínio sobre fenômenos da saúde e reabilitação. "Falar de funcionalidade" e incorporar consistentemente este enfoque na condução da prática clínica e da pesquisa envolvem compromissos distintos. A dificuldade de se implementar a perspectiva da funcionalidade tem sido frequentemente observada nas inconsistências teóricas e conceituais da literatura e da atuação clínica dos profissionais da saúde e da reabilitação.

Grande parte da literatura em saúde e reabilitação tem centrado na investigação da doença, sua sintomatologia e as consequências negativas de uma condição de saúde, caracterizando e descrevendo os sinais e sintomas da doença, bem como os distúrbios e limitaçóes apresentados por indivíduos que apresentam a doença, numa ótica linear. Nesse prisma, por exemplo, as alteraçóes e limitaçóes apresentadas por crianças com paralisia cerebral do tipo espástica são entendidas como padróes patogênicos, geralmente justificados pela presença da espasticidade (VAZ et al., 2006). Tal argumentação é de utilidade limitada para os profissionais da reabilitação. Embora a espasticidade seja um fenômeno real, a sua presença não é suficiente para justificar e explicar as limitaçôes funcionais apresentadas por essas crianças. Além disso, como muitas das intervençóes utilizadas por profissionais da reabilitaçáo não produzem efeitos importantes na modificação da espasticidade, a definição deste como sendo o fator responsável pelas alteraçóes funcionais de crianças com paralisia cerebral do tipo espástica sugeriria a ineficiência das açóes destes profissionais para a promoção de mudanças na funcionalidade da clientela. $O$ modelo linear de incapacidade, consistente com uma perspectiva restrita deste processo e uma visão reducionista da saúde, centra-se nas deficiências intrínsecas do indivíduo como forma de explicar o processo.

A perspectiva da funcionalidade humana é consistente com uma visão mais ampliada de saúde, de acordo com o modelo biopsicossocial, identificando o repertório de habilidades do indivíduo com determinada condição de saúde em relação às demandas funcionais e às características do ambiente (físico e sociocultural). Funcionalidade é resultante da interação entre a condição de saúde apresentada pelo indivíduo e os fatores do contexto (pessoal e ambiental) em que ele vive (WORLD..., 2001). Nesta perspectiva, os fatores limitantes que interferem na funcionalidade extrapolam o indivíduo e incluem informações sobre a tarefa funcional e sobre o contexto em que a função acontece.

No aspecto da funcionalidade, a partir de uma visão sistêmica, padróes utilizados para realizar atividades e tarefas da rotina diária são resultantes das inter-relaçóes entre os recursos disponíveis ao indivíduo para a realização de tarefas com demandas específicas, em determinado ambiente. O fenômeno de interesse deixa de centrar-se na condição de saúde do indivíduo (i.e., criança com paralisia cerebral) e sua sintomatologia, passando a incluir como elementos essenciais as demandas funcionais e as características do contexto. A lógica da funcionalidade é consistente com princípios de outros formalismos complexos, tais como impredicatividade ${ }^{3}$ definicional do fenômeno, mutualismo animal-ambiente, contingência (dependência do âmbito) da unidade funcional, entre outros.

\subsection{Pós-graduação, pesquisa e produção de conhecimento}

O investimento no desenvolvimento de pesquisa e na produção científica tem contribuído para o fortalecimento da Terapia Ocupacional no País. Uma vez que a comunicação dos trabalhos de pesquisa apresenta-se ainda incipiente na Terapia Ocupacional, meu compromisso com a publicação científica torna-se revelador. Como resultado, fui contemplada com bolsa de produtividade do $\mathrm{CNPq}$ (nível 1C e, mais recentemente, 1B), tornando-me 
a primeira e, até o momento, a única terapeuta ocupacional com esta classificação no País. Em consequência, tive a oportunidade de ocupar cargos de representação em instituições externas à UFMG (CNPq, CAPES, WFOT).

Ao refletir sobre as marcas que tenho deixado em minha trajetória acadêmica, percebo que, num primeiro momento, contribuí para o desenvolvimento de uma estrutura que pudesse viabilizar a pesquisa e que servisse de base para a pós-graduaçáo stricto senso.

\section{Peroração: perspectivas para novos caminhos}

Relembrando o meu caminhar, percebo que esta história tem estrutura dinâmica, na qual cada elemento deste processo náo aconteceu por acaso, tendo oferecido condiçóes necessárias para emergência de uma nova fase. Muitas trilhas foram percorridas, destas, alguns novos caminhos foram abertos e outros consolidados. Algumas estruturas foram reorganizadas, outras emergiram com força e vigor, possibilitando a pesquisa e a produçáo de conhecimento em Terapia Ocupacional, desenvolvimento infantil e reabilitação.

E o futuro, o que guarda para mim? O que será que está por vir? Quais os novos caminhos a serem percorridos? Que outras trilhas serão exploradas? Haverá outras marcas que serão deixadas? As respostas a estas perguntas ainda náo foram determinadas. Vislumbro algumas novas direçôes a seguir. Quero contribuir com o projeto de crescimento institucional do Departamento de Terapia Ocupacional, náo só nas atividades de ensino e no projeto pedagógico para a implantação do novo currículo do curso de Graduação, mas também na criação de linhas de pesquisa que sejam consistentes com a nova proposta curricular, reafirmando, assim, meu compromisso com a consistência ensino-pesquisa.

Permaneço fiel ao meu compromisso com o programa de Pós-Graduação em Ciências da Reabilitação e gostaria de continuar contribuindo para o seu fortalecimento, possibilitando um avanço na formação teórico-metodológica dos discentes e no processo de crescimento e de inserção internacional do programa, buscando parcerias intra e interinstitucionais.

Da mesma forma, planejo contribuir com o novo curso de mestrado em Terapia Ocupacional da Universidade Federal de Sáo Carlos, na qualidade de colaboradora, repassando experiências adquiridas na UFMG. Assumirei com muito empenho e dedicação a importante funçáo de editora da Revista Brasileira de Fisioterapia, buscando dar continuidade à trajetória ascendente desse prestigioso veículo de publicaçáo científica da área, iniciada pelos editores que nos antecederam. Tais direçôes certamente não seguirei sozinha e contarei com a companhia de velhos e novos parceiros.

Não me sinto uma obra acabada. Minha história tem sido escrita ao longo destes anos, e continua sendo, sem ainda a prescrição de um final. Sou o que já fui e o que estou agora e, em meio a tantas outras trilhas por serem percorridas, vou consolidando o que foi construído e abrindo novos caminhos. Meu caminhar nunca foi solitário, pois tive o privilégio de encontrar parceiros espetacularmente admiráveis, os quais transformaram o percurso em uma grande jornada. Muito ainda tenho para caminhar e nas trilhas que hão de vir vou mantendo o meu estilo, rompendo, inovando e (re)construindo, não tenho vontade de parar.

\section{Agradecimentos}

Meus mais sinceros agradecimentos a Ana Paula Serrata Malfitano, pela sua generosidade no auxílio para a publicação deste ensaio, a partir do material apresentado no concurso para professor titular do Departamento de Terapia Ocupacional da UFMG. Sem sua valiosa contribuição, não teria sido possível atender aos prazos para publicação neste número do periódico Cadernos de Terapia Ocupacional da UFSCar.

\section{Referências}

BENNETT, S. et al. Evidence-based practice in Occupational Therapy: international initiatives. World Federation of Occupational Therapists - WFOT Bulletin, Hong Kong, v. 53, p. 6-10, May 2006.

DRUMMOND, A. F. A formação inicial do terapeuta ocupacional: estudos dos currículos do curso de Terapia Ocupacional da Universidade Federal de Minas Gerais. 1999. 189 f. Dissertação (Mestrado em Educação)Faculdade de Educação, Universidade Federal de Minas Gerais, Belo Horizonte, 1999.

FONSECA, S. T. et al. Abordagem ecológica à percepçãoação: fundamentação para o comportamento motor. Brazilian Journal of Motor Behavior, Porto Alegre, v. 2, n. 1, p. 1-18, 2007.

GIBSON, J. J. The ecological approach to visual perception. Hillsdale, NJ: Lawrence Erlbaum Associates, 1986.

HALEY, S. M. et al. Pediatric evaluation of disability inventory (PEDI): development, standardization and administration manual. version 1.0. Boston, MA: Trustees of Boston University, Health and Disability Research Institute, 1992. 
JIRSA, V. K.; KELSO, J. A. S. Coordination Dynamics: issues and trends. Berlim: Springer, 2004.

KELSO, J. A. S. Dynamic patterns: self-organization of brain and behavior. Cambridge: MIT Press, 1995.

KIELHOFNER, G. Model of human occupation: theory and application. Baltimore: Lippincott Williams \& Wilkins, 1985.

MANCINI, M. C. Predicting elementary school participation in children with disabilities. 1997. $143 \mathrm{f}$. Thesis (Doctor of Science in Therapeutic Studies)-Boston University, Sargent College of Health \& Rehabilitation Sciences, Boston, 1997.

MANCINI, M. C. Inventário de avaliação pediátrica de incapacidade (PEDI): manual da versão brasileira adaptada. Belo Horizonte: UFMG, 2005.

MANCINI, M. C.; COELHO, Z. A. C. Raciocínio clínico em Terapia Ocupacional. In: DRUMMOND, A. F.; RESENDE, M. B. (Orgs.). Intervençôes em Terapia Ocupacional. Belo Horizonte: UFMG, 2008. cap. 1, p. 13-24.

MANCINI, M. C. et al. Perfil do desenvolvimento neuromotor do bebê de alto risco no primeiro ano de vida. Temas Sobre Desenvolvimento, São Paulo, v. 2, n. 8, p. 3-8, 1992.

MANCINI, M. C. et al. Predicting elementary school participation in children with disabilities. Archives of
Physical Medicine and Rehabilitation, Philadelphia, v. 81, n. 3, p. 339-347, mar. 2000. http://dx.doi.org/10.1016/ S0003-9993(00)90081-9

MANCINI, M. C. Impact of preterm birth on infants' visual orientation at term and eye-hand performance at 12 months of age. 1989. $85 \mathrm{f}$. Dissertation (Master of Science in Occupational Therapy)-University of Alberta, Faculty of Rehabilitation Medicine, Edmonton, Alberta, 1989.

PIPER, M. C.; DARRAH, J. Motor assessment of the developing infant. Philadelphia: W. B. Saunders Company, 1994.

ROGOFF, B. Apprenticeship in thinking. New York: Oxford University Press, 1990.

TESIO, L. Functional assessment in rehabilitative medicine. Eura Medicophysica, Torino, v. 43, n. 4, p. 1-9, Dec 2007.

VAZ, D. V. et al. Alteraçōes musculares em indivíduos com lesão do neurônio motor superior. Fisioterapia e Pesquisa, São Paulo, v. 13, n. 2, p. 71-82, 2006.

WORLD HEALTH ORGANIZATION - WHO. International classification of functioning, disability and health (ICF). Genebra: WHO, 2001.

WORLD HEALTH ORGANIZATION - WHO. International Classification of Impairment, Disability and Handicap (ICIDH). Genebra: WHO, 1980.

\section{Notas}

${ }^{1}$ Os termos assimilação e exploração referem-se aos conceitos propostos por Piaget e Thelen e Smith, respectivamente, para descrever processos de mudança no comportamento.

${ }^{2}$ O envolvimento em atividades administrativas na UFMG recentemente tomou nova dimensão, tendo assumido o cargo de Pró-Reitora Adjunta de Pesquisa, em agosto de 2011, a convite do Prof. Renato de Lima Santos, Pró-Reitor de Pesquisa, com mandato até 2014 .

${ }^{3}$ Definição impredicativa de um fenômeno refere-se ao direcionamento utilizado para explicação deste fenômeno. Neste tipo de definiçáo, o funcionamento de um sistema náo pode ser explicado a partir de suas subunidades. Vide: Turvey, M.T. Impredicativity, dynamics and the perception-action divide. In: (JIRSA; KELSO, 2004). 